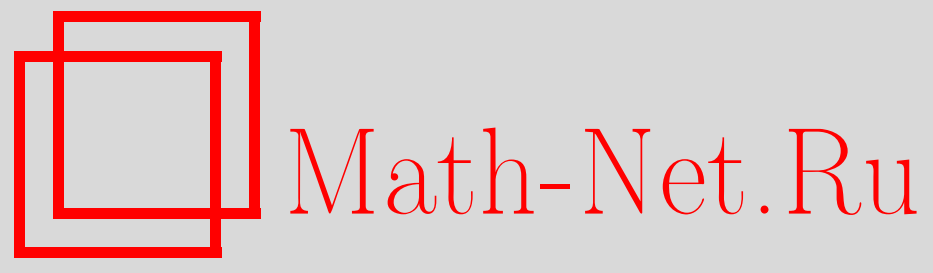

E. V. Murashkin, Yu. N. Radayev, Об одном дифференциальном ограничении в континуальной механике растущих тел, Вестн. Сам. гос. техн. ун-та. Сер. Физ.-мат. науки, 2019, номер 4, 646-656

DOI: https://doi.org/10.14498/vsgtu1696

Использование Общероссийского математического портала MathNet.Ru подразумевает, что вы прочитали и согласны с пользовательским соглашением

http://www.mathnet.ru/rus/agreement

Параметры загрузки:

IP: 107.22 .136 .117

26 апреля 2023 г., $17: 15: 24$

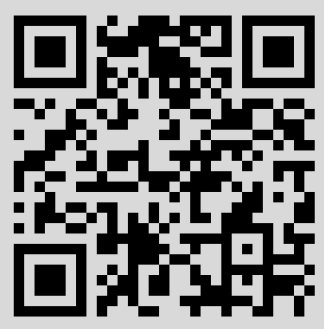




\title{
Mechanics of Solids
}

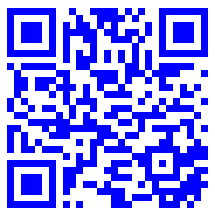

MSC: 74A20, 74A60

\section{On a differential constraint in the continuum theory of growing solids}

\author{
E. V. Murashkin, Yu. N. Radayev
}

A. Ishlinsky Institite for Problems in Mechanics, Russian Academy of Sciences, 101, pr. Vernadskogo, Moscow, 119526, Russian Federation.

\begin{abstract}
The present paper is devoted to the problem of boundary conditions formulation for asymmetric problems in the mechanics of growing solids (MGS). The boundary conditions on the propagating growing surface (PGS) is the fundamental problem of this branch of mechanics. Results from the algebra of rational invariants are used for deriving constitutive equations on PGS. Geometrically and mechanically consistent differential constraints are obtained on PGS. Those are valid for a wide range of materials and metamaterials. A number of constitutive equations on PGS of different complexity levels are proposed. The boundary conditions simultaneously can be treated as differential constraints within the frameworks of variational formulations. The differential constraints imply an experimental identification of constitutive functions. For this reason, the obtained results furnish a general ground in applied problems of the MGS.
\end{abstract}

Keywords: 3D printing, surface growth, stress, constitutive equation, rational invariant, differential constraint, complete system.

Received: 30 ${ }^{\text {th }}$ April, 2019 / Revised: $12^{\text {th }}$ August, $2019 /$

Accepted: $16^{\text {th }}$ September, $2019 /$ First online: $18^{\text {th }}$ November, 2019

\section{Research Article}

() (1) The content is published under the terms of the Creative Commons Attribution 4.0 International License (http://creativecommons.org/licenses/by/4.0/)

Please cite this article in press as:

Murashkin E. V., Radayev Yu.N. On a differential constraint in the continuum theory of growing solids, Vestn. Samar. Gos. Tekhn. Univ., Ser. Fiz.-Mat. Nauki [J. Samara State Tech. Univ., Ser. Phys. Math. Sci.], 2019, vol. 23, no. 4, pp. 646-656. doi: 10.14498/vsgtu1696.

\section{Authors' Details:}

Evgenii V. Murashkin (10) https://orcid.org/0000-0002-3267-4742

Cand. Phys. \& Math. Sci., PhD, MD; Senior Researcher; Lab. of Modeling in Solid Mechanics; e-mail: evmurashkin@google.com

Yuri N. Radayev (iD https://orcid.org/0000-0002-0866-2151

D.Sc. (Phys. \& Math. Sci.), Ph.D., M.Sc., Professor; Leading Researcher; Lab. of Modeling in Solid Mechanics; e-mail: radayev@ipmnet.ru, y.radayev@gmail.com 


\section{Introduction}

Traditional methods of manufacturing products of complex shape imply a variety of technological processes. Such processes are coupled with the removal of material and based on the synthesis of products by successively adding material to a surface of complex shape. Manufacturing products by adding new material is widely used in modern engineering [1]. Such additive manufacturing methods include: laser stereolithography [2], selective laser sintering [3], electron beam melting [4], fusion simulation, multi-jet modeling method [5], manufacturing by lamination, 3D printing [6-8], computer axial lithography [9], layer-by-layer concreting [10].

$3 \mathrm{D}$ printing $(3 \mathrm{DP})$ is similar to selective laser sintering technology, but melting isn't used here. An object is formed from powder material by gluing, using inkjet printing to apply liquid glue. 3D printing technology allows color modeling by adding dyes to the adhesive (directly during printing), or by using multiple printheads with color glue [6-8].

Layer-by-layer concreting of constructions also belongs to the methods of additive technologies [10]. Layer-by-layer concreting can be divided into two types, depending on the time between layer fills. In the case of a "hot seam," the break between the layers is less than 12 hours. The second type of layer-by-layer filling is a "cold seam." In this case, it is necessary to wait for the complete hardening of the previous layer to exclude the possible cracking of the non-hardened part under the action of the newly added material.

The additive manufacturing techniques described above basically use wellknown ideas from natural processes: accretion of space objects, the formation of avalanches and glaciers, crystal growth processes, the growth of atherosclerotic plaques $[11,12]$. All these phenomena are characterized by presence of PGS. The growth of atherosclerotic plaque can be described as the process of initial infiltration of blood plasma components into a thin surface layer of the inner wall of the artery. The growth of a crystal nucleus occurs by adding individual atoms or their groups to crystal surface.

A solution of applied problem of growing solids mechanics is sometimes a sophisticated and time-consuming procedure [13-19]. An substantial feature of the formulation of boundary value problems of the MGS is the formulation of boundary conditions on the interface between the source material and the added part [20-22]. In this paper, several variants of the constitutive equations on the growing surface are discussed, starting from the simplest relations (see the book by G. I. Bykovtsev: [22, Pp. 288-292]) to some significant generalizations of the theory. Throughout the paper the terminology and notations adopted in the publications [16-19,22,24] are used.

\section{Rate equations of mechanics of growing solids (MGS)}

The governing equations in MGS are often conveniently furnished as the rate equations. In this case, the equilibrium equation formulated in an arbitrary spatial system of curvilinear coordinates $x^{k}(k=1,2,3)$ for the asymmetric stress tensor can be presented as partial differential equation

$$
\nabla_{j}\left(\partial . \sigma^{j i}\right)+\partial . X^{i}=0
$$


where $\sigma^{i j}$ is the Cauchy force stress tensor, $X^{i}$ is the volume forces, $\nabla_{j}$ is the covariant differential operator with respect to a given spatial metrics, $\partial$. is the time derivative take with fixed spatial coordinates $x^{k}$.

In order to close the system of differential equations, it is required to specify constitutive equations according to the constitutive law which is an intrinsic characteristics of a particular solid/process. A model of growing solid should also be supplemented by boundary conditions on PGS.

Growing surface $\Sigma$ propagating in space is determined by an implicit form equation:

$$
t=\stackrel{*}{\tau}\left(x^{i}\right)
$$

In this case, the unit normal vector $\mathbf{n}$ on the surface $\Sigma$ directed towards its propagation is given by the spatial gradient as follows

$$
n_{i}=c \partial_{i}^{*}, \quad c=\left|\nabla_{\tau}^{*}\right|^{-1}
$$

where $c$ is the linear velocity of PGS in the normal direction $\mathbf{n}$, which is defined according to

$$
c=\lim _{\delta t \rightarrow 0} \frac{\left|\overrightarrow{P P^{\prime}}\right|}{\delta t} .
$$

Here $\left|\overrightarrow{P P^{\prime}}\right|$ is the length of normal vector directed from an arbitrary point $P$ on PGS at time $t$ to point $P^{\prime}$ which is intersection of normal vector $\mathbf{n}$ and PGS at time $t+\delta t$.

To find out the force stress tensor by the given rates of stresses, one can employ the formulae given in [22]:

$$
\begin{aligned}
\sigma^{i j} & =\int_{\tau+0}^{t}\left[\partial . \sigma^{i j}\left(x^{k}, t^{\prime}\right)\right] d t^{\prime}+\mathfrak{I}^{j i}+\sigma^{*} i j\left(x^{k}\right), \\
\mathfrak{I}^{i j} & =\int_{\tau-0}^{*+0}\left[\partial . \sigma^{i j}\left(x^{k}, t^{\prime}\right)\right] d t^{\prime},
\end{aligned}
$$

where $\mathfrak{I}^{i j}$ — stress jump related integral, $\stackrel{*}{\sigma}^{i j}\left(x^{k}\right)=\left.\sigma^{i j}\left(x^{k}, t\right)\right|_{t=*\left(x^{s}\right)-0}$ are the force stress tensor components at the time $t=\stackrel{*}{\tau}\left(x^{s}\right)-0$ right before an element starting formation of the main solid. The time $t={ }^{*}\left(x^{s}\right)+0$ corresponds to moment right after an element has been attached to PGS. In order to simplify script of formulas we retain $t=\stackrel{*}{\tau}\left(x^{s}\right)$ instead of a more correct $t=\stackrel{*}{\tau}\left(x^{s}\right)+0$.

After substituting of actual stresses (2) into the equilibrium equation

$$
\nabla_{j} \sigma^{j i}+X^{i}=0
$$

one can readily come to

$$
\nabla_{j}\left\{\int_{\tau}^{t}\left[\partial . \sigma^{j i}\left(x^{k}, t^{\prime}\right)\right] d t^{\prime}+\mathfrak{I}^{i j}+\stackrel{*}{\sigma}^{j i}\left(x^{k}\right)\right\}+X^{i}=0 \quad(t \geqslant \stackrel{*}{\tau}+0)
$$


After transformations according to the rule of differentiation of the integral depending on a parameter, the equation (4) is turned to

$$
\begin{aligned}
\int_{\tau}^{t} \nabla_{j}\left[\partial . \sigma^{j i}\left(x^{k}, t^{\prime}\right)\right] d t^{\prime}+\nabla_{j} \mathfrak{I}^{j i}-\left.\left(\nabla_{j}^{*}\right)\left[\partial . \sigma^{j i}\left(x^{k}, t\right)\right]\right|_{t={ }_{\tau}^{*}\left(x^{s}\right)}+ \\
+\nabla_{j}^{*} \sigma^{j i}\left(x^{k}\right)+X^{i}=0 .
\end{aligned}
$$

Upon substituting the Eq. (1) in Eq. (5)

$$
\begin{aligned}
\int_{\tau}^{t} \nabla_{j}\left[\partial . \sigma^{j i}\left(x^{k}, t^{\prime}\right)\right] d t^{\prime}+\nabla_{j} \mathfrak{I}^{j i}-\left.c^{-1} n_{j}\left[\partial . \sigma^{j i}\left(x^{k}, t\right)\right]\right|_{t=\mathcal{\tau}^{*}\left(x^{s}\right)}+ \\
+\nabla_{j}{ }^{*}{ }^{j i}\left(x^{k}\right)+X^{i}=0 .
\end{aligned}
$$

The following equation can be obtained by integrating (6) and taking account of (3), then changing the order of derivatives

$$
-X^{i}+\left.X^{i}\right|_{t=\tau_{\tau}^{*}\left(x^{s}\right)}+\nabla_{j} \mathfrak{J}^{j i}-\left.c^{-1} n_{j}\left[\partial . \sigma^{j i}\left(x^{k}, t\right)\right]\right|_{t=\tau^{*}\left(x^{s}\right)}+\nabla_{j}^{*} \sigma^{j i}\left(x^{k}\right)+X^{i}=0 .
$$

After rearrangement of terms Eq. (7) reads

$$
c\left[\nabla_{j} \sigma^{j i}\left(x^{k}\right)+\nabla_{j} \mathfrak{I}^{j i}+\left.X^{i}\right|_{t=*\left(x^{s}\right)}\right]-\left.n_{j}\left[\partial . \sigma^{j i}\left(x^{k}, t\right)\right]\right|_{t=*\left(x^{s}\right)}=0 .
$$

Hereinafter the notation $\left.(\cdot)\right|_{t=*\left(x^{s}\right)}$ will be dropped out for values calculated on PGS. form

Finally, the constitutive boundary condition on PGS can be formulated in

$$
c\left[\nabla_{j}{ }^{*}{ }^{j i}\left(x^{k}\right)+\nabla_{j} \mathfrak{I}^{j i}+X^{i}\right]-n_{j}\left[\partial . \sigma^{j i}\left(x^{k}, t\right)\right]=0 \quad(t \geqslant \stackrel{*}{\tau}+0) .
$$

The Eq. (9) should be considered as a differential constraint for stresses on PGS. If it is possible to express the stresses $\underset{\boldsymbol{\sigma}}{*}$ in terms of the actual stresses $\left.\boldsymbol{\sigma}\right|_{t=* *\left(x^{s}\right)}$, then from the equation (8) we can derive the differential equation for stresses. Alternative approaches to the boundary conditions derivation are discussed in detail, for example, in [20,21].

In the general case, the stresses $\underset{\boldsymbol{\sigma}}{*}$ are to be expressed in terms of the actual stresses on PGS by a tensor constitutive equation

$$
\stackrel{*}{\boldsymbol{\sigma}}=\mathfrak{F}(\boldsymbol{\sigma}, \mathbf{n}, \ldots) .
$$

Omitted arguments of the function $\mathfrak{F}$ in the Eq. (10) stand as additional parameters characterizing the growth process. Those can be related to multiphysics phenomena. In a simple model, list of additional parameters may be empty. In particular, the function $\mathfrak{F}$ may depend on the microstructural directors and the thermophysical hidden variables associated with PGS. The physical sense of the

\footnotetext{
${ }^{1}$ The spatial coordinates $x^{k}$ are the parameters, and the lower limit of integration depends on $x^{k}$.
} 
additional directors [23-26] may be associated with the characteristic directions of the fibers laying in woven composite materials, reinforcement in concrete structures, winding of threads in a bobbin, etc. The function $\mathfrak{F}$, in fact, should depend on combinations of arguments which are invariant under coordinate-frame rotations around of the director $\mathbf{n}$.

\section{A simple formulation of differential constraint on PGS}

Consider in further details a geometric interpretation of the case discussed earlier in [22]. Let traction vector $\mathbf{t}$ be known or prescribed on PGS:

$$
\mathbf{t}=\mathbf{n} \cdot \boldsymbol{\sigma}
$$

In this case, we introduce the following notation $\underset{2 d}{\boldsymbol{*}}$ for the reduced tensor $\stackrel{*}{\boldsymbol{\sigma}}$ to the two-dimensional plane element $T$ and assume a simple form of the Eq. (10) as follows

$$
\underset{2 d}{\stackrel{*}{\sigma}}=\underset{2 d}{\mathfrak{F}}(\mathbf{t}, \mathbf{n})
$$

Tensors $\underset{2 d}{\stackrel{*}{\boldsymbol{\sigma}}}$ and $\underset{2 d}{\mathfrak{F}}$ are represented in the Cartesian coordinate frame by $2 \times 2$ matrices

$$
\underset{2 d}{\stackrel{*}{\boldsymbol{\sigma}}}=\left(\begin{array}{ll}
\sigma_{11} & \sigma_{12} \\
\sigma_{21} & \sigma_{22}
\end{array}\right), \quad \underset{2 d}{\mathfrak{F}}=\left(\begin{array}{ll}
\mathfrak{F}_{11} & \mathfrak{F}_{12} \\
\mathfrak{F}_{21} & \mathfrak{F}_{22}
\end{array}\right) .
$$

Hereafter, it is convenient to use the decomposition of the traction vector $\mathbf{t}$ into the parts

$$
\mathbf{t}=\mathbf{t}_{\perp}+\mathbf{t}_{\|}
$$

Here $\mathbf{t}_{\perp}$ is the projection of the traction vector on the tangent plane $T$ to the instantaneous PGS, $\mathbf{t}_{\|}$denotes the projection on the normal direction.

As for arguments of the tensor function $\mathfrak{F}$, we choose the joint rational invariants of the second-rank tensor $\boldsymbol{\sigma}$ and the unit vector $\mathbf{n}$, which are unchanged under coordinate frame rotations around the director $\mathbf{n}$. In this case, we write the rationally independent system of invariants [27] in the following form

$$
|\mathbf{t}|^{2}=\mathbf{t} \cdot \mathbf{t}, \quad\left|\mathbf{t}_{\|}\right|=|\mathbf{t} \cdot \mathbf{n}|, \quad\left|\mathbf{t}_{\perp}\right|^{2} .
$$

There is an obvious rational syzygy in the system of invariants (11)

$$
|\mathbf{t}|^{2}=\left|\mathbf{t}_{\|}\right|^{2}+\left|\mathbf{t}_{\perp}\right|^{2}
$$

After eliminating the first invariant from (11) the system of independent rational invariants takes the following form

$$
\left|\mathbf{t}_{\|}\right|, \quad\left|\mathbf{t}_{\perp}\right|^{2} .
$$

The constitutive equation on PGS, taking account of (12), can be furnished in the form

$$
\underset{2 d}{\stackrel{*}{\boldsymbol{\sigma}}}=\underset{2 d}{\mathfrak{F}}\left(\left|\mathbf{t}_{\|}\right|,\left|\mathbf{t}_{\perp}\right|^{2}\right)
$$

The equation (13) has a clear mechanical sense. We choose a Cartesian coordinate system so that the unit vector $\mathbf{k}$ is directed along the normal $\mathbf{n}$ to PGS, 
and for the projection of the traction vector $\mathbf{t}$ in the tangent plane $T$ to PGS, the following equation is valid

$$
\left|\mathbf{t}_{\perp}\right|^{2}=\left|\mathbf{t}_{\perp} \cdot \boldsymbol{\imath}\right|^{2}+\left|\mathbf{t}_{\perp} \cdot \boldsymbol{\jmath}\right|^{2} .
$$

Then the projections of the vector $\mathbf{t}$ onto the unit vectors of the specified coordinate system can be expressed in terms of actual stresses by

$$
\left|\mathbf{t}_{\|}\right|=\left|\sigma_{\langle 33\rangle}\right|, \quad\left|\mathbf{t}_{\perp} \cdot \boldsymbol{\imath}\right|^{2}=\sigma_{\langle 31\rangle}^{2}, \quad\left|\mathbf{t}_{\perp} \cdot \boldsymbol{\jmath}\right|^{2}=\sigma_{\langle 32\rangle}^{2} .
$$

As a result, the constitutive equation (13) is rewritten in the form

$$
\underset{2 d}{\stackrel{*}{\boldsymbol{\sigma}}}=\underset{2 d}{\mathfrak{F}}\left(\left|\sigma_{\langle 33\rangle}\right|, \sigma_{\langle 31\rangle}^{2}+\sigma_{\langle 32\rangle}^{2}\right)
$$

Note that the equation (15) is similar to those discussed in [22]. However, contrary to the work of [22], the tensor $\mathfrak{F}$ is not isotropic, i.e. four constitutive functions are to be determined on PGS. ${ }^{2 d}$

Substituting the Eq. (15) into the equation (8), keeping in mind that $\mathbf{n}=\mathbf{k}$ and introducing notation $\langle\ldots\rangle$ for indices in the specific coordinate frame, we obtain the differential constraints on PGS in coordinate form

$$
c\left[d_{\langle j\rangle} \mathfrak{F}_{\langle j i\rangle}+X_{\langle i\rangle}\right]-\partial . \sigma_{\langle 3 i\rangle}\left(x_{\langle k\rangle}, t\right)=0(\langle i\rangle,\langle j\rangle=1,2,3),
$$

In Eq. (16) values $X_{\langle i\rangle}$ and $\partial . \sigma_{\langle 3 i\rangle}$ must be considered on PGS. Furthermore, $d_{\langle j\rangle}$ denotes the directional derivatives:

$$
d_{\langle 3\rangle}=\mathbf{n} \cdot \nabla, \quad d_{\langle 1\rangle}=\boldsymbol{\imath} \cdot \nabla, \quad d_{\langle 2\rangle}=\boldsymbol{\jmath} \cdot \nabla
$$

In Eq. (17) index $\langle 3\rangle$ corresponds to the direction of the normal, and indices $\langle 1\rangle$ and $\langle 2\rangle$ to the tangent directions to PGS. Indepth discussion of directional operators $d_{\langle j\rangle}$ apparatus see in monograph [28].

Note that the system of independent joint rational invariants (12) is not complete. It does not take account of joint invariants containing the squares of the force stress tensor $\boldsymbol{\sigma}$.

\section{A full invariant formulation of differential constraint on PGS}

A complete system of joint rational invariants of the second-rank tensor $\boldsymbol{\sigma}$ and the vector $\mathbf{n}$, in addition to the invariants (12), includes invariants

$$
\left.\left|\mathbf{t}_{2}\right||=| \mathbf{t}_{2} \cdot \mathbf{n}|, \quad| \mathbf{t}_{\perp}\right|^{2}, \quad\left|\mathbf{t}_{\perp} \cdot \mathbf{t}_{2}\right|^{2} .
$$

In the equation (18), the vector $\underset{2}{\mathbf{t}}$ is defined according to

$$
\underset{2}{\mathbf{t}}=\mathbf{n} \cdot \boldsymbol{\sigma}^{2}, \quad \underset{2}{\mathbf{t}}=\mathbf{t} \cdot \boldsymbol{\tau}, \quad \underset{2}{t_{s}}=n_{j} \sigma^{j i} \sigma_{i s}=t^{i} \sigma_{i s} .
$$

\footnotetext{
${ }^{2}$ There will be three constitutive functions in the symmetric case. Only one constitutive function remains for the isotropic symmetric case.
} 
Following to the discussion in the previous section, for the vector $\underset{2}{\mathbf{t}}$ we adopt the decomposition

$$
\underset{2}{\mathbf{t}}=\mathbf{t}_{2} \|+\mathbf{t}_{\perp} \text {. }
$$

As $\left(\varpi\right.$ is the angle determined by directions $\mathbf{t}_{\perp}$ and $\underset{2}{\mathbf{t}_{\perp}}$ )

$$
\left|\mathbf{t}_{\perp} \cdot \underset{2}{\mathbf{t}_{\perp}}\right|^{2}=\left|\mathbf{t}_{\perp}\right|^{2}\left|\mathbf{t}_{2}\right|^{2} \cos ^{2} \varpi
$$

then one can replace the invariant $\left|\mathbf{t}_{\perp} \cdot \mathbf{t}_{2}\right|^{2}$ in (18) by $\cos ^{2} \varpi$.

The complete system of joint rational invariants of the stress tensor $\boldsymbol{\sigma}$ and the vector $\mathbf{n}$ takes the form

$$
\left|\mathbf{t}_{\|}\right|, \quad\left|\mathbf{t}_{\perp}\right|^{2}, \quad \underset{2}{\mid \mathbf{t}_{\|}}\left|, \quad \underset{2}{\mid \mathbf{t}_{\perp}}\right|^{2}, \quad\left|\mathbf{t}_{\perp} \cdot \underset{2}{\mathbf{t}_{\perp}}\right|^{2} .
$$

The constitutive equation (10) on PGS in terms of the complete system of joint rational invariants (19) of the asymmetric second-order tensor $\boldsymbol{\sigma}$ and the vector $\mathbf{n}$ for reduced tensors onto the two-dimensional plane element $T$ takes the form

$$
\underset{2 d}{\stackrel{*}{\boldsymbol{\sigma}}}=\underset{2 d}{\mathfrak{F}}\left(\left|\mathbf{t}_{\|}\right|,\left|\mathbf{t}_{\perp}\right|^{2}, \mathbf{t}_{2}||,\left|\mathbf{t}_{2}\right|^{2},\left|\mathbf{t}_{\perp} \cdot \underset{2}{\mathbf{t}_{\perp}}\right|^{2}\right) .
$$

We choose, as in the previous case, the Cartesian rectangular coordinate system so that the unit vector $\mathbf{k}$ is directed along the normal $\mathbf{n}$ to PGS. For the projection of the traction vector $\mathbf{t}$ in the tangent plane $T$, we assume (14) to PGS, and for the vector $\mathbf{t}_{2}$ obvious equality is satisfied

$$
\left|\mathbf{t}_{\perp}\right|^{2}=\left|\underset{2}{\mathbf{t}_{\perp}} \cdot \boldsymbol{\imath}\right|^{2}+|\underset{2}{\mathbf{t}} \perp \cdot \boldsymbol{\jmath}|^{2}
$$

The invariants (12) and (19) and projection lengths (14) and (21) are calculated via the actual stresses $\boldsymbol{\sigma}$ on the surface $\Sigma$ according to

$$
\begin{aligned}
& \left|\mathbf{t}_{\perp} \cdot \boldsymbol{\imath}\right|^{2}=\sigma_{\langle 31\rangle}^{2}, \quad\left|\mathbf{t}_{\perp} \cdot \boldsymbol{\jmath}\right|^{2}=\sigma_{\langle 32\rangle}^{2}, \quad\left|\mathbf{t}_{\|}\right|=\left|\sigma_{\langle 33\rangle}\right|, \\
& \left|\mathbf{t}_{\perp} \cdot \boldsymbol{\imath}\right|^{2}=\left|\sigma_{\langle 31\rangle} \sigma_{\langle 11\rangle}+\sigma_{\langle 32\rangle} \sigma_{21}+\sigma_{\langle 33\rangle} \sigma_{\langle 31\rangle}\right|^{2}, \\
& \left|\mathbf{t}_{\perp} \cdot \boldsymbol{\jmath}\right|^{2}=\left|\sigma_{\langle 31\rangle} \sigma_{\langle 12\rangle}+\sigma_{\langle 32\rangle} \sigma_{\langle 22\rangle}+\sigma_{\langle 33\rangle} \sigma_{\langle 32\rangle}\right|^{2}, \\
& \left|\mathbf{t}_{2}\right|=\left|\sigma_{\langle 31\rangle} \sigma_{\langle 13\rangle}+\sigma_{\langle 32\rangle} \sigma_{\langle 23\rangle}+\sigma_{\langle 33\rangle}^{2}\right|, \\
& \left|\mathbf{t}_{\perp} \cdot \mathbf{t}_{\perp}\right|^{2}=\mid \sigma_{\langle 31\rangle}^{2} \sigma_{\langle 11\rangle}+\sigma_{\langle 31\rangle} \sigma_{\langle 32\rangle} \sigma_{21}+\sigma_{\langle 31\rangle}^{2} \sigma_{\langle 33\rangle}+ \\
& \quad+\sigma_{\langle 32\rangle} \sigma_{\langle 31\rangle} \sigma_{\langle 12\rangle}+\sigma_{\langle 32\rangle}^{2} \sigma_{\langle 22\rangle}+\left.\sigma_{\langle 32\rangle}^{2} \sigma_{\langle 33\rangle}\right|^{2} .
\end{aligned}
$$

The latter equation containing cubics in stresses should be classified as never discussed and used in the mechanics of solids. 
The constitutive equation on PGS (20) taking account of the expressions (22) after introducing following notation

$$
\begin{gathered}
\mathrm{I}=\left|\sigma_{\langle 33\rangle}\right|, \quad \mathrm{II}=\sigma_{\langle 31\rangle}^{2}+\sigma_{\langle 32\rangle}^{2}, \quad \mathrm{III}=\left|\sigma_{\langle 31\rangle} \sigma_{\langle 13\rangle}+\sigma_{\langle 32\rangle} \sigma_{\langle 23\rangle}+\sigma_{\langle 33\rangle}^{2}\right|, \\
\mathrm{IV}=\left|\sigma_{\langle 31\rangle} \sigma_{\langle 11\rangle}+\sigma_{\langle 32\rangle} \sigma_{\langle 21\rangle}+\sigma_{\langle 33\rangle} \sigma_{\langle 31\rangle}\right|^{2}+\left|\sigma_{\langle 31\rangle} \sigma_{\langle 12\rangle}+\sigma_{\langle 32\rangle} \sigma_{\langle 22\rangle}+\sigma_{\langle 33\rangle} \sigma_{\langle 32\rangle}\right|^{2}, \\
\mathrm{~V}=\mid \sigma_{\langle 31\rangle}^{2} \sigma_{\langle 11\rangle}+\sigma_{\langle 31\rangle} \sigma_{\langle 32\rangle} \sigma_{\langle 21\rangle}+\sigma_{\langle 31\rangle}^{2} \sigma_{\langle 33\rangle}+\sigma_{\langle 32\rangle} \sigma_{\langle 31\rangle} \sigma_{\langle 12\rangle}+ \\
+\sigma_{\langle 32\rangle}^{2} \sigma_{\langle 22\rangle}+\left.\sigma_{\langle 32\rangle}^{2} \sigma_{\langle 33\rangle}\right|^{2} .
\end{gathered}
$$

can be rewritten in functional form

$$
\underset{2 d}{\stackrel{*}{\sigma}}=\underset{2 d}{\mathfrak{F}}(\mathrm{I}, \mathrm{II}, \mathrm{III}, \mathrm{IV}, \mathrm{V})
$$

or in a simplified variant

$$
\underset{2 d}{\stackrel{*}{\boldsymbol{\sigma}}}=\underset{2 d}{\mathfrak{F}}(\mathrm{I}, \mathrm{II}, \mathrm{III}, \mathrm{IV})
$$

The boundary conditions in the form of differential constraints on PGS (8), in the case when the added material has microstructural features, can be generalized by introducing in arguments of the function (10) the additional microstructural directors associated with the characteristic directions of the laying of the material in the processes of winding threads or the production of woven composites.

\section{Conclusion}

1. In present study, geometrically and mechanically consistent boundary conditions on PGS in the form of differential constraints have been obtained and discussed.

2. A general form of the mentioned constraints for the asymmetric force stress tensor has been obtained. It is valid for a wide range of materials and metamaterials.

3. The arguments of the constitutive tensor function on PGS have been determined by a set of invariants that are constant with respect to the rotations of the coordinate frame.

4. A geometric interpretation of the simplest variant of the differential constraint has been considered. A full invariant formulation has been proposed.

5. The developed approach must involve the experimental identification of the constitutive tensor functions on PGS.

6. The obtained results afford a general ground in applied studies on the MGS with an asymmetric force stress tensor.

Competing interests. We declare that we have no competing interests.

Authors' contributions and responsibilities. Each author has participated in the article concept development and in the manuscript writing. The authors are absolutely responsible for submitting the final manuscript in print. Each author has approved the final version of manuscript.

Funding. This work was supported by the Russian Science Foundation (project no. 17-19-01257).

Acknowledgments. The authors are grateful to the reviewer for careful reading of the paper and valuable suggestions and comments. 


\section{References}

1. Berman B. 3-D printing: The new industrial revolution, Business Horizons, 2012, vol. 55, no. 2, pp. 155-162. doi: 10.1016/j.bushor.2011.11.003.

2. Mankovich N. J., Cheeseman A. M., Stoker N. G. The display of three-dimensional anatomy with stereolithographic models, J. Digit. Imaging, 1990, vol. 3, no. 3, pp. 200-203. doi: 10. $1007 /$ bf 03167610 .

3. Stampfl J., Baudis S., Heller C., et al. Photopolymers with tunable mechanical properties processed by laser-based high-resolution stereolithography, J. Micromech. Microeng., 2008, vol. 18, no. 12, 125014. doi : 10.1088/0960-1317/18/12/125014.

4. Murr L. E., Gaytan S. M., Ceylan A., et al. Characterization of titanium aluminide alloy components fabricated by additive manufacturing using electron beam melting, Acta Materialia, 2010, vol.58, no.5, pp. 1887-1894. doi:10.1016/j.actamat.2009.11.032.

5. Bauer W., Knitter R., Emde A., et al. Replication techniques for ceramic microcomponents with high aspect ratios, Microsystem Technologies, 2002, vol. 9, no. 1-2, pp. 81-86. doi: 10 . $1007 / \mathrm{s} 00542-002-0200-z$.

6. Rengier F., Mehndiratta A., von Tengg-Kobligk H., et al. 3D printing based on imaging data: review of medical applications, Int. J. Comput. Assist. Radiol. Surg., 2010, vol.5, no. 4, pp. 335-341. doi: 10.1007/s11548-010-0476-x.

7. Lipson H., Kurman M. Fabricated: The new world of $3 D$ printing. Indiana, John Wiley \& Sons, 2013.

8. Ventola C. L. Medical applications for 3D printing: current and projected uses, Pharmacy and Therapeutics, 2014, vol. 39, no. 10, pp. 704-711.

9. Ozel T., Bourret G. R., Mirkin C. A. Coaxial lithography, Nature Nanotechnology, 2015, vol. 10, no. 4, pp. 319-324. doi : 10.1038/nnano.2015.33.

10. Panda B., Paul S. C., Hui L. J., et al. Additive manufacturing of geopolymer for sustainable built environment, Journal of Cleaner Production, 2017, vol.167, pp. 281-288. doi: 10. 1016/j.jclepro.2017.08.165.

11. Stadnik N. E., Dats E. P. Continuum mathematical modelling of pathological growth of blood vessels, Journal of Physics: Conference Series, 2018, vol.991, 012075. doi: 10.1088/ 1742-6596/991/1/012075.

12. Stadnik N. E., Murashkin E. V., Dats E. P. Residual stresses in blood vessel wall during atherosclerosis, AIP Conference Proceedings, 2019, vol.2116, no. 1, 380013. doi: 10.1063/ 1.5114394 .

13. Southwell R. V. An introduction to the theory of elasticity. For engineers and physicists, Oxford Engineering Science Series. London, Oxford Univ. Press, 1936.

14. Rashba E. I. Stresses computation in massive construction under their own weight taking into account the construction sequence, Proc. Inst. Struct. Mech. Acad. Sci. Ukrainian SSR, 1953, no. 18, pp. 23-27 (In Russian).

15. Charlab V. D. Linear creep theory of the build-up body. Mechanics of rod systems and solid mediums, In: The Proceedings of the Leningrad Construction Institute, vol. 49. Leningrad, Leningrad Construction Institute, 1966, pp. 93-119 (In Russian).

16. Arutyunyan N. Kh., Naumov V. E., Radayev Yu. N. Dynamic expansion of an elastic layer. Part 1. Motion of a flow of precipitated particles at a variable rate, Izv. Akad. Nauk. Mekh. Tverd. Tela, 1992, no. 5, pp. 6-24 (In Russian).

17. Arutyunyan N. Kh., Naumov V. E., Radayev Yu. N. Dynamical expansion of an elastic layer. Part 2. The case of drop of accreted particles at a constant rate, Izv. Akad. Nauk. Mekh. Tverd. Tela, 1992, no. 6, pp. 99-112 (In Russian).

18. Naumov V. E., Radayev Yu. N. Thermomechanical model of an growing solids: Variational formulation, Preprint no. 527. Moscow, IPMech RAS, 1993, 39 pp. (In Russian)

19. Dmitrieva A. M., Naumov V. E., Radayev Yu. N. Growth of thermoelastic spherical layer: Application of the variational approach, Preprint no. 528. Moscow, IPMech RAS, 1993, 64 pp. (In Russian) 
20. Arutyunyan N. Kh., Naumov V. E. The boundary value problem of the theory of viscoelastic plasticity of a growing body subject to aging, J. Appl. Math. Mech., 1984, vol.48, no. 1, pp. 1-10. doi: 10.1016/0021-8928(84)90099-6.

21. Trincher V. K. On the formulation of the problem of stresses calculation in the gravitational state of a growing solid, Izv. Akad. Nauk SSSR. Mekh. Tverd. Tela, 1984, no. 2, pp. 119-124 (In Russian).

22. Bykovtsev G. I. Izbrannye problemnye voprosy mekhaniki deformiruemykh sred [Selected Problems from Solid Mechanics. Collection of articles]. Vladivostok, Dal'nauka, 2002 (In Russian).

23. Kovalev V. A., Radayev Yu. N. Mathematical models and contemporary theories of physical fields, Izv. Saratov Univ. (N.S.), Ser. Math. Mech. Inform., 2009, vol. 9, no. 4(2), pp. 41-94 (In Russian). doi : 10.18500/1816-9791-2009-9-4-2-41-94.

24. Kovalev V. A., Radayev Yu. N. Volnovye zadachi teorii polia i termomekhanika [Wave Problems of Field Theory and Thermomechanics]. Saratov, Saratov State Univ., 2010 (In Russian).

25. Kovalev V. A., Radayev Yu. N. On precisely conserved quantities of coupled micropolar thermoelastic field, Izv. Saratov Univ. (N.S.), Ser. Math. Mech. Inform., 2012, vol. 12, no. 4, pp. 71-79 (In Russian). doi : 10.18500/1816-9791-2012-12-4-71-79.

26. Kovalev V. A., Radayev Yu. N. Covariant field equations and $d$-tensors of hyperbolic thermoelastic continuum with fine microstructure, Izv. Saratov Univ. (N.S.), Ser. Math. Mech. Inform., 2013, vol.13, no.2(1), pp. 60-68 (In Russian). doi: 10.18500/ 1816-9791-2013-13-2-1-60-68.

27. Gurevich G. B. Foundations of the theory of algebraic invariants. Groningen, P. Noordhoff, 1964.

28. Radayev Yu. N. Prostranstvennaia zadacha matematicheskoi teorii plastichnosti [Threedimensional Problem of the Mathematical Theory of Plasticity]. Samara, Samara State Univ., 2007 (In Russian). 
Вестн. Сам. гос. техн. ун-та. Сер. Физ.-мат. науки. 2019. Т. 23, № 4 . С. $646-656$ ISSN: 2310-7081 (online), 1991-8615 (print)

УДК 539.319

\title{
Об одном дифференциальном ограничении в континуальной механике растущих тел
}

\author{
Е. В. Мурашкин, Ю. Н. Радаев
}

Институт проблем механики им. А. Ю. Ишлинского РАН, Россия, 119526, Москва, просп. Вернадского, 101, корп. 1.

\section{Аннотация}

Предлагается один общий принцип постановки граничных условий в краевых задачах механики растущих тел. При выводе определяющих соотношений на поверхности наращивания используется аппарат алгебры рациональных инвариантов. Проведен вывод различных вариантов физически непротиворечивых дифференциальных ограничений на поверхности наращивания. Полученные условия справедливы для весьма широкого круга материалов и метаматериалов. Для использования сформулированных дифференциальных ограничений в конкретных приложениях необходима их экспериментальная идентификация. По этой причине полученные результаты могут служить общей основой в прикладных исследованиях по механике растущих тел.

Ключевые слова: 3D-печать, поверхностный рост, напряжение, определяющее уравнение, рациональный инвариант, дифференциальное ограничение, полная система.

Получение: 30 апреля 2019 г. / Исправление: 12 августа 2019 г. / Принятие: 16 сентября 2019 г. / Публикация онлайн: 18 ноября 2019 г.

Конкурирующие интересы. Заявляем, что в отношении авторства и публикации этой статьи конфликта интересов не имеем.

Авторский вклад и ответственность. Все авторы принимали участие в разработке концепции статьи и в написании рукописи. Авторы несут полную ответственность за предоставление окончательной рукописи в печать. Окончательная версия рукописи была одобрена всеми авторами.

Финансирование. Работа выполнена при поддержке Российского научного фонда (проект № 17-19-01257).

Благодарности. Авторы благодарят рецензента за внимательное прочтение статьи, ценные предложения и комментарии.

\section{Научная статья}

(2)(7) Контент публикуется на условиях лицензии Creative Commons Attribution 4.0 International (https://creativecommons.org/licenses/by/4.0/deed.ru)

Образец для цитирования

Murashkin E. V., Radayev Yu. N. On a differential constraint in the continuum theory of growing solids, Vestn. Samar. Gos. Tekhn. Univ., Ser. Fiz.-Mat. Nauki [J. Samara State Tech. Univ., Ser. Phys. Math. Sci.], 2019, vol. 23, no. 4, pp. 646-656. doi: 10.14498/vsgtu1696.

\section{Сведения об авторах}

Евгений Валервевич Мурашкин (10) https://orcid.org/0000-0002-3267-4742

к.ф.-м.н.; старший научный сотрудник; лаб. моделирования в механике деформируемого твердого тела; e-mail: evmurashkin@google.com

Юрий Николаевич Радаев (D) https://orcid.org/0000-0002-0866-2151

доктор физико-математических наук, профессор; ведущий научный сотрудник; лаб. моделирования в механике деформируемого твердого тела; e-mail:radayev@ipmnet.ru, y.radayev@gmail.com 